Received: 2016.12.18 Accepted: 2017.02.20 Published: 2017.05.11

\title{
Syringocystadenoma Papilliferum of the External Auditory Canal
}

Authors' Contribution:

Study Design A

Data Collection B

Statistical Analysis C

Data Interpretation D

Manuscript Preparation E

Literature Search F

Funds Collection $G$
A 1 Luca Bruschini

E 1 Annalisa Ciabotti

D 1 Andrea De Vito

B 1 Francesca Forli

F 1 Christina Cambi

C 2 Eugenio Maria Ciancia

A 1 Stefano Berrettini
1 Ear, Nose, Throat (ENT) Audiology and Phoniatry Unit, University Hospital of Pisa, Pisa, Italy

2 Department of Pathology, University Hospital of Pisa, Pisa, Italy
Corresponding Author: Conflict of interest:

Patient: $\quad$ Male, 72

Final Diagnosis:

Symptoms:

Medication:

Clinical Procedure:

Specialty:

Syringocystadenoma papilliferum

Hearing loss

-

\section{Excisional biopsy}

Otolaryngology

Objective: Rare disease

Background: Ceruminous glands are modified apocrine glands, situated in the external auditory canal, that, together with sebaceous glands, produce cerumen, better known as ear wax. The neoplastic transformation of these structures is very rare and there have been few cases reported in the literature.

Case Report: Syringocystadenoma papilliferum is one of the rarest tumors among benign tumors arising from the ceruminous glands. We here report the case of a 72-year-old man with a lesion histologically documented as a syringocystadenoma papilliferum and we review the literature, focusing our attention on clinical features and treatment options of benign glandular tumors arising from the external auditory canal.

Conclusions: Syringocystadenoma papilliferum is a rare benign tumor of the ceruminous glands of the external ear canal. Excision biopsy is mandatory for the diagnosis and is the best treatment.

MeSH Keywords:

Adenoma, Pleomorphic • Cystadenoma, Serous • Ear Canal

Full-text PDF: http://www.amjcaserep.com/abstract/index/idArt/902900

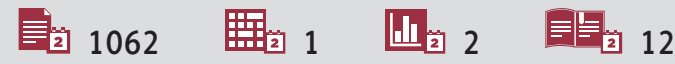




\section{Background}

Ceruminous glands are modified apocrine glands, located in the cartilaginous two-thirds of the external auditory canal (EAC) in the deepest part of the derma. The degeneration of these glands is very rare and has only occasionally been reported in the literature. Some authors believe that benign ceruminous gland tumors represent $5.7 \%$ of all ear and EAC tumors [1]. Others have suggested an even lower frequency [2-5]. The age of affected patients ranges from 12 to 85 years old, with a mean age of 53 years [1]. No etiological agent has been identified to be involved in ceruminous gland degeneration.

Neoplasms arising from the ceruminal glands of the EAC represent a diagnostic challenge because of their variety in clinical and histological manifestations. Firstly, they are rare in humans (but are often described in cats and dogs), resulting in a difficult diagnosis for general surgical pathologists. Secondly, to add more confusion, many descriptions have been used to describe this kind of tumor, resulting in a variable nomenclature that includes synonyms such as hidradenoma, cylindroma, mixed tumor of skin, and aural hydradenoma.

The literature on ceruminous benign tumors is limited to case reports and small group cases, and there is a lack of large comprehensive evaluation.
In this case report we describe the clinical manifestation and histological features of one of the many varieties of ceruminous syringocystadenoma papilliferum described in the literature [6]. Adding our case to those already published, there are little more than a dozen cases of syringocystadenoma papilliferum reported in the literature [6].

\section{Case Report}

A 72-year-old man came to our attention with a left conductive hearing loss that had started at least 3 months earlier. He did not complain of pain, discharge, or other inflammatory signs involving the ear. The patient reported hearing loss, but no tinnitus or vertigo. Ear trauma or a history of prior surgery were not reported. At physical examination, we found that the external auditory canal was occluded by an oval lesion rising from the posterior canal wall. The maximum diameter was about $1 \mathrm{~cm}$. The consistency was taut-elastic and the skin over the lesion appeared normochromic and normotrophic. The lesion did not look like an inflammatory polyp, but rather like a neoplasm growing under the skin of the EAC. Because of the suspicion of this diagnosis, we did not suggest medical treatment, and instead recommended a computed tomography (CT) of the petrous bone. The CT scan revealed the presence of a $10 \times 6 \mathrm{~mm}$ oval mass in half of the external part of the posterior wall of the EAC, with no signs of bone erosion (Figure 1).

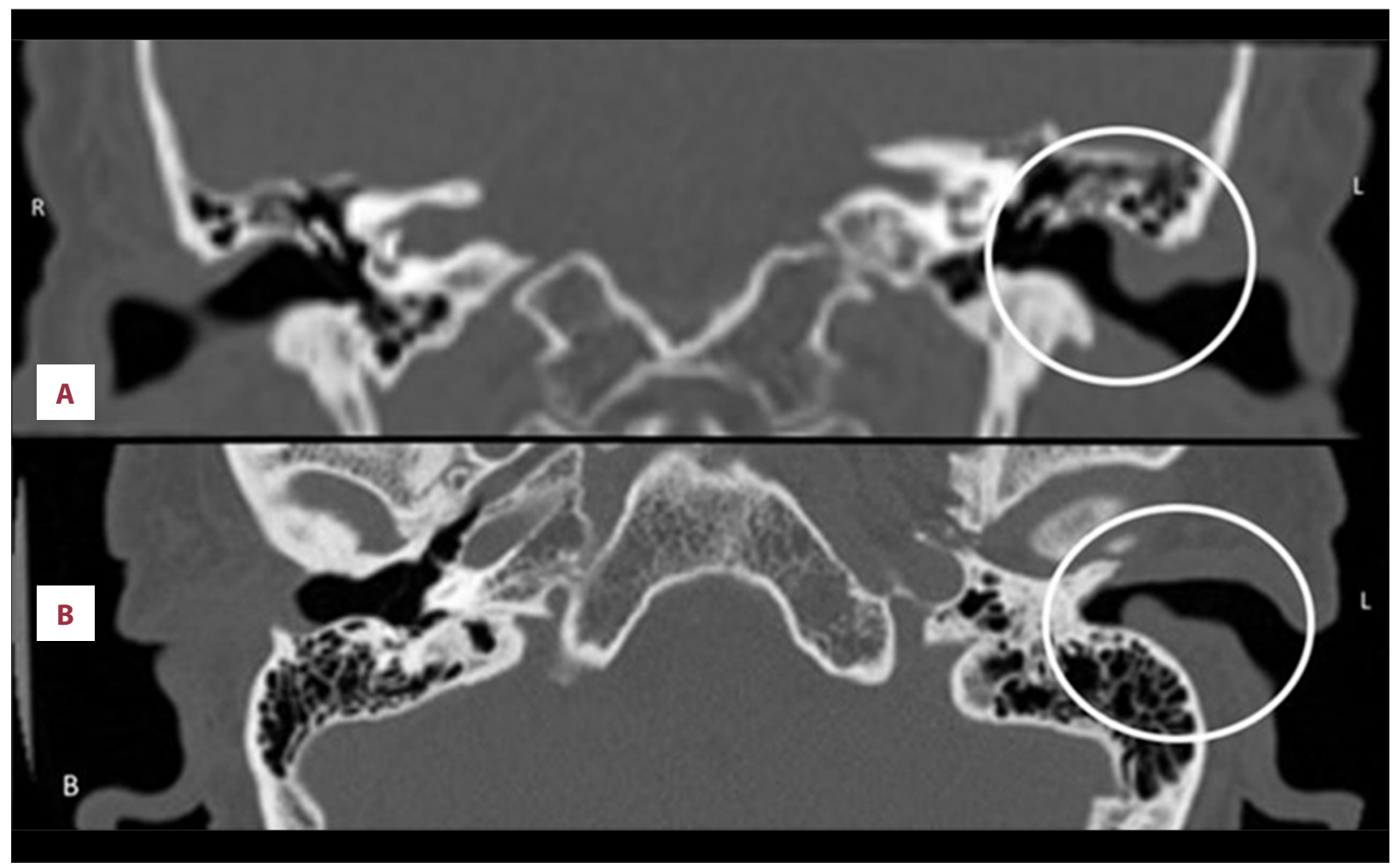

Figure 1. CT scan of the petrous bone, in the circle the lesion of the EAC. (A) Coronal image, (B) axial image. 


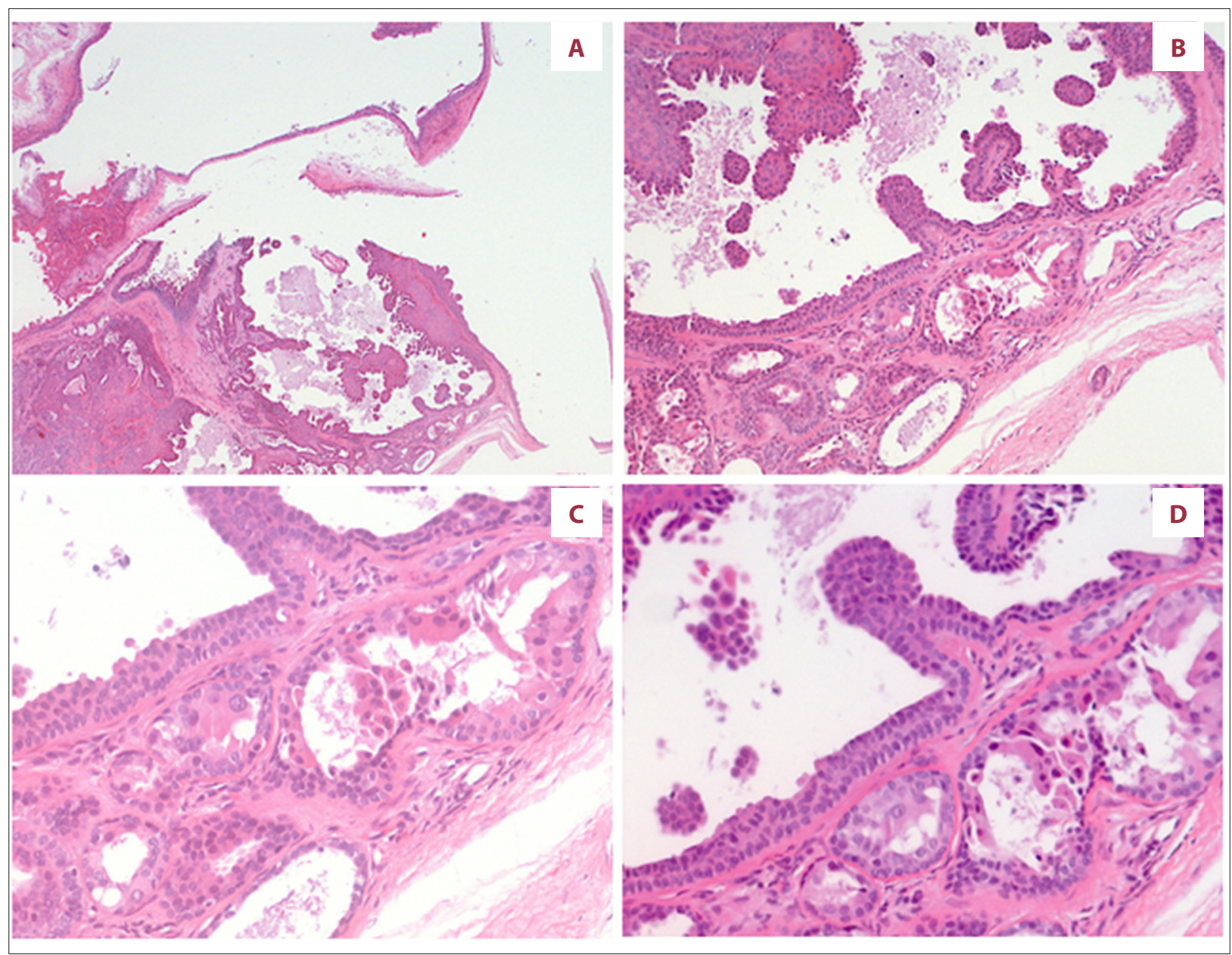

Figure 2. Ceruminous syringocystadenoma papilliferum of the external auditory canal, evaluation with hematoxylin-eosin staining. Note papillae lined by bilayered glandular epithelium projecting into a cystic lumen. Glandular structures show ceruminous decapitation secretion in the luminal cells subtended by a prominent, well-defined myoepithelial cell layer. (A) Original magnification 25x, (B) original magnification 100x; (C, D) original magnification 250x.

Because there was no indication for medical therapy, only surgical treatment was ordered. The surgical procedure was done under general anaesthesia. A retroauricular incision was made to visualize the skin and bone of the posterior canal wall, and the tumor was radically removed. The histological examination revealed the presence of a "syringocystadenoma papilliferum" (Figure 2).

After surgery, the patient said he no longer had hearing loss or other symptoms. At 12 months after surgery, no signs of recurrence were macroscopically evident.

\section{Discussion}

All ceruminous tumors arise from the external auditory canal, especially from the outer two-thirds, where the ceruminal glands are physiologically located. They infrequently invade the mastoid bone, the middle ear, and the skull base [1].
Ceruminous adenomas contain neoplastic cells arranged in various patterns: glandular, cystic, solid, within the same mass, or variably distributed. It is easy to find a dual cell population, composed of an inner luminal epithelial layer and a bas$\mathrm{al} /$ myoepithelial layer adjacent to the basement membrane; syringocystadenoma papilliferum specifically contains papillary projections into a cystic lumen, lined by a dual cell population of benign appearance. Luminal cells frequently reveal prominent apical caps with decapitation secretion, typical of apocrine glands like the ceruminous glands [1].

The persistent use of unsuitable terms in the literature in reference to ceruminous tumors has led to considerable confusion, resulting in incorrect classifications and inappropriate therapies when applied in everyday practice.

Ceruminous syringocystadenoma papilliferum has to be placed among the benign tumors of the external auditory canal, 
Table 1. Description of symptoms, site, size, treatment, and recurrence of ceruminous tumors in the literature $[1,3,5-7,11]$.

\begin{tabular}{|c|c|c|c|c|}
\hline Histology & N case & Invasion or metastasis & Treatments & Recurrent during follow-up \\
\hline \multirow{3}{*}{ Adenoma } & 52 & \multirow{2}{*}{ None } & Excisional biopsy & No \\
\hline & 5 & & $\begin{array}{l}\text { Incomplete excisional } \\
\text { biopsy }\end{array}$ & 5 recurrences \\
\hline & 1 & Invasion & Wide excision & No \\
\hline \multirow{6}{*}{ Adenocarcinoma } & 1 & \multirow{4}{*}{ Invasion } & Excisional biopsy & No \\
\hline & 1 & & $\begin{array}{l}\text { Excisional biopsy and } \\
\text { radiotherapy }\end{array}$ & 2 recurrences \\
\hline & 3 & & Radical mastoidectomy & No \\
\hline & 4 & & $\begin{array}{l}\text { Radical mastoidectomy and } \\
\text { radiotherapy }\end{array}$ & 4 recurrences \\
\hline & 1 & \multirow[b]{2}{*}{ None } & Wide excision & No \\
\hline & 1 & & $\begin{array}{l}\text { Wide excision and } \\
\text { radiotherapy }\end{array}$ & 1 \\
\hline \multirow{9}{*}{ Adenoid-cystic } & 4 & \multirow{3}{*}{ Invasion } & Wide excision & 1 \\
\hline & 4 & & Radical mastoidectomy & 1 \\
\hline & & & Excisional biopsy & 1 \\
\hline & 24 & \multirow[t]{2}{*}{ Multiple metastasis } & $\begin{array}{l}\text { Radical excision and } \\
\text { radiotherapy }\end{array}$ & $\begin{array}{l}\text { Numerous recurrences, } 12 \\
\text { died from metastasis }\end{array}$ \\
\hline & 1 & & Chemotherapy & Died \\
\hline & 4 & \multirow{4}{*}{ None } & $\begin{array}{l}\text { Wide excision and } \\
\text { radiotherapy }\end{array}$ & 2 \\
\hline & 1 & & Radical mastoidectomy & 1 and metastasis \\
\hline & 9 & & Wide excision & 6, 1 died \\
\hline & 1 & & Cauterization & 1 \\
\hline \multirow{2}{*}{$\begin{array}{l}\text { Syringocystadenoma } \\
\text { papilliferum }\end{array}$} & 3 & None & $\begin{array}{l}\text { Incisional biopsy and after } \\
\text { wide excision }\end{array}$ & No \\
\hline & 2 & None & Wide excisional biopsy & no \\
\hline
\end{tabular}

together with adenoma and chondroid syringoma, while for malignant forms, the nomenclature includes adenocarcinoma, adenoid-cystic carcinoma, and mucoepidermoid carcinoma $[5,7,8]$.

These distinct tumors have different treatments and different prognosis (Table 1). The possibility of recurrence in case of benign tumors, such as ceruminous adenoma and pleomorphic adenoma, seems to be related only to an incomplete surgical excision of the lesion. On the contrary, malignant tumors have a poor prognosis despite radical surgical treatment.

Because of its rarity, the ceruminous syringocystadenoma papilliferum has not been reported as a benign glandular tumor of the EAC. To date, only 12 cases of ceruminous syringocystadenoma papilliferum have been described in the literature [6].
Syringocystadenoma papilliferum is defined as a well-differentiated, localized, cystic tumor that shows papillary proliferation of glandular tissue, histologically similar to that of normal ceruminous glands. This tumor causes very few symptoms, usually nonspecific, that are related to its mass volume and degree of canal obstruction, including hearing loss, discharge or light bleeding, and mild to moderate pain [2-6,9].

Otoscopy often reveals a reddish lesion with a mean diameter of $1 \mathrm{~cm}$ with a cut surface occasionally containing small cysts. Surface ulceration occurs in the minority of cases, since the tumor is usually circumscribed by a pseudocapsule. Tumor size ranges from 0.4 to $2.0 \mathrm{~cm}$ due to the confined anatomical space of the EAC [1]. 
Differential diagnosis of ceruminous adenomas must include adenocarcinoma, neuroendocrine adenoma of the middle ear (NAME), parotid pleomorphic adenoma, meningioma, and paraganglioma [10].

Radiological studies are mandatory to evaluate ceruminous syringocystadenoma papilliferum. CT scanning can show the shape and dimensions of the lesion, as well as possible bone erosion. Kamakura et al. presented the MRI characteristics of an syringocystadenoma papilliferum of the EAC: intermediate signal intensity on T1- and T2-weighted images and slight enhancement on gadolinium enhanced T1-weighted images [11].

Appropriate treatment consists of excisional biopsy, with the necessity of further re-excision if the syringocystadenoma

\section{References:}

1. Thompson LD, Nelson BL, Barnes EL: Ceruminous adenomas: A clinicopathologic study of 41 cases with a review of the literature. Am J Surg Pathol, 2004; 28: 308-18

2. Dehner LP, Chen KT: Primary tumors of the external and middle ear: Benign and malignant glandular neoplasms. Arch Otolaryngol, 1980; 106: 13-19

3. Hicks GW: Tumors arising from the glandular structures of the external auditory canal. Laryngoscope, 1983; 93: 326-40

4. Mansour $P$, George MK, Pahor AL: Ceruminous gland tumours: A reappraisal. J Laryngol Otol, 1992; 106: 727-32

5. Michaels L, Thompson LDR: Ceruminous gland neoplasm of external auditory canal and cylindroma. In: Barnes L, Eveson JW, Reichart P, Sidransky D. Pathology and genetics of head and neck tumours. World Health Organization, Classification of Tumours, Lyon; 2005; 331-33

6. Arechvo A, Balseris S, Neverauskiene L, Arechvo I: Syringocystadenoma papilliferum of the bony external auditory canal: a rare tumor in a rare location. Case Rep Otolaryngol, 2013; 2013: 541679 papilliferum is not completely included in the surgical sample. Clinical follow-up is suggested because recurrences are not uncommon. Radiation and chemotherapy are not used to treat these types of neoplasms [12].

\section{Conclusions}

Syringocystadenoma papilliferum is a rare benign tumor of the ceruminous glands of the external ear canal. Excision biopsy is mandatory for the diagnosis and is the best treatment.

\section{Conflicts of interest}

None.

7. Elsürer C, Senkal HA, Baydar DE, Sennaroğlu L: Ceruminous adenoma mimicking furunculosis in the external auditory canal. Eur Arch Otorhinolaryngol, 2007; 264: 223-25

8. Mills RG, Douglas-Jones T, Williams RG: 'Ceruminoma' - a defunct diagnosis. J Laryngol Otol, 1995; 109: 180-88

9. Arato J, Michel RP, Baxter JD: Ceruminoma. J Otolaryngol, 1980; 9: 482-86

10. Droździk A, Kowalczyk R, Jworowska E et al: The role of Nrf2 in pathology of pleomorphic adenoma in parotid gland. Med Sci Monit, 2015; 21: 1243-48

11. Kamakura T, Horii A, Mishiro Y et al: Magnetic resonance imaging of syringocystadenoma papilliferumof the external auditory canal. Auris Nasus Larynx, 2006: 33: 53-56

12. Rana K, Rathore PK, Wadhwaa V et al: Syringocystadenoma papilliferum of external auditory canal and pinna: A rare presentation. Int J Ped Otorhinolar Extra, 2014; 9: 157-59 